\title{
STUDY ON THE CHEMICAL CONSTITUENTS AND ANTIBACTERIAL ACTIVITY OF ESSENTIAL OIL OF ACORUS CALAMUS L. RHIZOMES OF RUPENDEHI DISTRICT (NEPAL)
}

\author{
Susan Joshi*, Sundar Bashyal \\ Central Department of Chemistry, Tribhuvan University, Kirtipur, Kathmandu, Nepal \\ *Corresponding author: susanjoshi68@gmail.com
}

(Received: September 16, 2018; Revised: October 11, 2018; Accepted: October 15, 2018)

\begin{abstract}
The essential oil from the air dried powder of wild Acorus calamus L. rhizomes was isolated using Clevenger-type hydrodistillation apparatus and its chemical constituents were analyzed by gas chromatography-mass spectrometric (GCMS) analysis. A total numbers of fourteen chemical constituents were identified and quantified occupying $100 \%$ of total oil composition. The major chemical constituents are reported to be $\beta$-asarone (68.96 \%), 4-hydroxy-4-methyl-2pentanone $(8.73 \%)$ shyobunone $(8.65 \%)$, p-methoxyphenyl butanone $(4.16 \%)$ and the minor chemical constituents are $\delta$-cadinene $(0.84 \%)$, isoelemicine $(2.68 \%)$, muurolene $(1.92 \%)$ and cis-ocimene $(1.44 \%)$. The antibacterial activity of the essential oil isolated from the wild Acorus calamus L. rhizomes was carried out using paper disc method against one Gram positive bacteria of Staphylococcus aureus and three Gram negative bacteria of Escherichia coli, Klebsiella pneumoniae and Proteus vulgaris. The isolated essential oil from the dry powder of Acorus calamus L. rhizome showed a good potentiality of the antibacterial effect against tested bacteria.
\end{abstract}

Keywords: Acorus calamus L., Rhizomes, Essential oil, $\beta$-asarone, Isoelemicine, Escherichia coli

\section{INTRODUCTION}

Acorus calamus L. of the genus Acorus belong to the family Acoraceae. It is known as BHOJO in Nepal and commonly known as sweet flag. It is reported that about 40 species of Acorus is distributed from temperate to sub tropical wetland and native of central Asia and Eastern European countries (Gilani et al. 2006, Agarwal et al.1956). This plant species grow along swamp, rivers, lakes and marshy places up to 2000 meters altitude in different parts of Nepal and the Himalayas of India (Raina et al. 2003, Kim et al. 2009). It is about two meters of height with stout and knobby shallow branching rhizomes. Tufts of basal leave occur at intervals along these rhizomes while coarse fibrous roots develop below and the plant multiplies by its rhizomes. The rhizome is long indefinite branched, smooth, pinkish or pale green and it is internally whitish pink in color with pleasant aroma and slightly bitter in taste (Balakumbahan et al. 2010).

Acorus calamus L. has been used as traditional folk medicine in Nepal (Satyal et al. 2013). In America and Indonesia, it is used for cure of gastrointestinal disorder such as colic pain, diarrhea and in the therapy of diabetics (Gilani et al. 2006, Si et al. 2010). It has been an integral part of Indian and Chinese medicinal systems for hundreds of years (Wu et al. 2009, Lee et al. 2011). People of Baitadi and Darchula districts of Nepal utilize the juice of the Acorus calamus L. rhizome as an anthelmintic and it is chewed to treat coughs, cold and sore throat (Satya et al. 2013, Uprety et al. 2011). This plant contains bioactive chemical constituents such as essential oils, alkaloids, steroids, phenols, coumarins, flavonoids etc which are valuable for treating various human ailments (Balakumbahan et al.2010). Despite an insufficient research works on the chemical components and bioactivities of Acorus calamus L., there is a dearth of information about its secondary metabolites and biological activities. Therefore, the present study is aimed to investigate the essential oil composition of the rhizome of air dried wild Acorus calamus L. from Rupandehi district of Nepal using GC-MS analysis and to evaluate their antibacterial activities.

\section{MATERIALS AND METHODS}

\section{Plant material}

The air dried wild Acorus calamus L. rhizome was collected in the month of April 2011 from marshy places of Devdaha-9, Rupandehi district, Nepal which is located in $27^{\circ} 40^{\prime} 48^{\prime \prime} \mathrm{N}$ and $83^{\circ} 34^{\prime} 12^{\prime \prime} \mathrm{E}$ at about 250 meters above the sea level. The plant was identified at Central Department of Botany, Tribhuvan University, Kirtipur, Nepal. The rhizomes were washed with cold water to remove the contaminant soil and allowed to air dry in shade at room temperature for about two months and crushed to get powder using electrical grinder.

\section{Extraction of essential oil}

The essential oil from the powdered Acorus calamus L. rhizome was extracted using Clevenger-type hydrodistillation apparatus. Amount of 100 grams of the powdered sample was kept in a round bottom flask along with distilled water and fitted with Clevenger-type distillation apparatus. The content of the flask was heated 
in heating mantle at boiling temperature for 4 hours followed by standing for one hour at room temperature. The isolated essential oil was dried using anhydrous sodium sulphate and stored in airtight reagent bottle at 4 ${ }^{\circ} \mathrm{C}$ for further analysis.

\section{GC-MS analysis}

The essential oil obtained from the wild Acorus calamus L. rhizomes was analyzed by GC-mass spectrometer (QP2010, Shimadzu Co. of Japan) operated in the electron impact (EI) mode with the electron energy of $70 \mathrm{eV}$ and ion source temperature of $200{ }^{\circ} \mathrm{C}$ under the following conditions: injection volume of $1 \mu \mathrm{L}$ with split ratio of 1:90; Helium as carrier gas at $1 \mathrm{ml} / \mathrm{min}$ constant flow mode, injector temperature of $280{ }^{\circ} \mathrm{C}$, oven temperature of 40 to $250{ }^{\circ} \mathrm{C}$ at the rate of $7{ }^{\circ} \mathrm{C} / \mathrm{min}$. Mass spectra were recorded in the scan range between 35-500 atomic mass units. Identification of the chemical constituents was based on their retention indices determined by reference and comparison of their mass spectral fragmentation patterns using previously reported references, and NIST 05, WILEY and SZTERP libraries.

\section{Antibacterial screening test}

Antibacterial evaluation of the essential oil was performed using the paper disc diffusion method elaborated by Bauer et al. (1960). Bacterial strains were collected from Center Department of Microbiology, Tribhuvan University, Kirtipur. The studied strains include Gram-positive bacteria (Staphylococcus aureus) and Gram-negative bacteria (Escherichia coli, Klebsiella pneumoniae and Proteus vulgaris). For the positive control, tetracycline paper disc was taken and petroleum ether disc was taken for negative control. The zone of inhibition was obtained by measurement of the radius from the centre of the disc to the edge of the inhibition growth (Oliver et al. 1959) and the obtained values were converted in percentage of zone of inhibition.

\section{RESULTS AND DISCUSSION}

The amount of isolated essential oil obtained from the powder form of the air dried wild Acorus calamus L. rhizome was quantified and was found to be $0.8 \% \mathrm{v} / \mathrm{w}$ on dry weight basis. The extracted oil was pale yellow color and slightly viscous with sweet herbal aroma. Different chemical constituents of the essential oil isolated from the air dried wild Acorus calamus L. rhizomes are tabulated in Table 1. The GC-mass spectrometric analysis of the isolated essential oil revealed the presence of all together fourteen chemical components in the gas chromatogram (Fig. 1) and representing $100 \%$ of total isolated oil compositions. The chemical types of secondary metabolites were monoterpene hydrocarbons, alcohol derivative of monoterpene, sesquiterpenes, carbonyl compound and ester derivatives. The major chemical constituents identified were of $\beta$-asarone $(68.96 \%)$, 4 hydroxy-4-methyl-2-pentanone $(8.73 \%)$ shyobunone $(8.65 \%)$, p-methoxyphenyl butanone (4.16\%), isoelemicine $(2.68 \%)$ and the minor chemical constituents of $\delta$-cadinene $(0.84 \%)$ and cis-ocimene $(1.44$ $\%)$ with a little amount of cuparene $(0.29 \%)$ and other secondary metabolites. $\alpha$-asaron was not detected in the isolated oil. Some of the chemical constituents having same chemical composition are on different retention time (Rt).

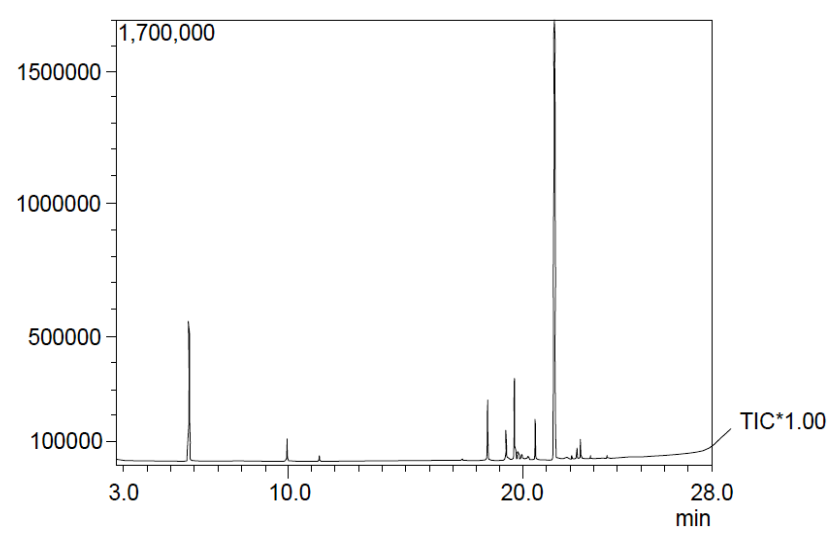

Fig. 1. Gas chromatogram of the isolated essential oil of Acorus calamus $\mathrm{L}$.rhizome collected from Rupandehi district of Nepal

The present study revealed that the chemical constituents of the different essential oil and their percentages are different from previously published works of Nepal and Indian origin (Uttarakhand, India). The major component of the essential oils from the plant of Eastern Nepal (Biratnagar) origin and Indian (Uttarakhand) origin was reported $\beta$-asarone of 84.0-86.9 \% (Satyal et al. 2013, Gyawali \& Kim 2009) and of 81.1-92.4\% (Bist et al. 2011) with other minor chemical constituents. Similarly, a very high amount of $\beta$-asarone was reported from Acorus calamus L. rhizomes found all over India and other places of world (Raina et al. 2003).

The result of the antibacterial screening test of essential oil isolated from Acorus calamus L. rhizomes at different concentration $(0.25,0.50,0.75$ and $1.00 \mathrm{mg} / \mathrm{disc})$ is depicted in Fig. 2. The essential oil was found to be equally active against Staphylococcus aureus, Klebsiella pneumoniae, Escherichia coli and Proteus vulgaris in $0.25 \mathrm{mg} / \mathrm{disc}$ concentration. Among these four bacteria, good potential antibacterial effect was shown against Klebsiella pneumoniae at $1.0 \mathrm{mg} /$ disc concentration. The potential antibacterial activity of this essential oil attributed to $\beta$-asarone as well as synergistic effect of other complex chemical compositions present in natural product either in major or minor amounts. 
Table 1. Chemical constituents of the isolated essential oil of Acorus calamus L. rhizome collected from Rupandehi district of Nepal

\begin{tabular}{|c|c|c|c|c|c|}
\hline S. No. & $\begin{array}{c}\text { Chemical Compounds } \\
\end{array}$ & MW & Rt (min.) & Area $(\%)$ & Identification Methods \\
\hline 1 & 4-Hydroxy-4-methyl-2-pentanone & 116 & 5.749 & 8.73 & Rt, MS \\
\hline 2 & Cis-Ocimene & 136 & 9.952 & 1.44 & Rt, MS \\
\hline 3 & Linalool & 154 & 11.338 & 0.42 & Rt, MS \\
\hline 4 & p-Methoxyphenyl butanone & 178 & 18.507 & 4.16 & $\mathrm{Rt}, \mathrm{MS}$ \\
\hline 5 & Shyobunone & $\begin{array}{l}220 \\
220\end{array}$ & $\begin{array}{l}19.641 \\
19.286\end{array}$ & 8.65 & Rt, MS \\
\hline 6 & $\delta$-Cadinene & 204 & 19.789 & 0.84 & Rt, MS \\
\hline 7 & $\begin{array}{l}\text { Bicyclo }\{6.3 .0\} \text { undec-1(8)-en-3 } \\
\text { one, } 2,2,5,5 \text {,tetramethyl }\end{array}$ & 220 & 19.928 & 0.59 & Rt, MS \\
\hline 8 & Kessane & 222 & 19.992 & 0.32 & Rt, MS \\
\hline 9 & Isoelemicin & 208 & 20.536 & 2.68 & Rt, MS \\
\hline 10 & $\begin{array}{c}\beta \text {-asarone }(1,2,4, \text { trimethoxy-5- } \\
\text { propenylbenzene })\end{array}$ & 208 & $\begin{array}{l}21.336 \\
22.292 \\
\end{array}$ & 68.96 & Rt, MS \\
\hline 11 & $\begin{array}{l}\text { Propanoic acid,2-[4-(1-buten-3-pheny- } \\
\text { methy ester }\end{array}$ & 218 & 21.45 & 0.62 & Rt, MS \\
\hline 12 & $\alpha$-Cadinol & 222 & 22.062 & 0.38 & Rt, MS \\
\hline 13 & Muurolene & 220 & $\begin{array}{l}22.223 \\
22.433\end{array}$ & 1.92 & Rt, MS \\
\hline 14 & Cuparene & 202 & 22.851 & 0.29 & $\mathrm{Rt}, \mathrm{MS}$ \\
\hline
\end{tabular}

$\beta$-asarone revealed beneficial in cognitive impairment associated disorders such as Alzeimer disease (McGraw et al. 2002). Quantitative differences in the amount of $\beta$ asarone in the air dried wild Acorus calamus L. rhizomes essential oil have been considered to have taxonomic importance within the genus (Rost et al. 1979). Differences in the chemical compositions and yield of the essential oil are mostly due to different environmental condition, geographical location and time of collection of plant materials.

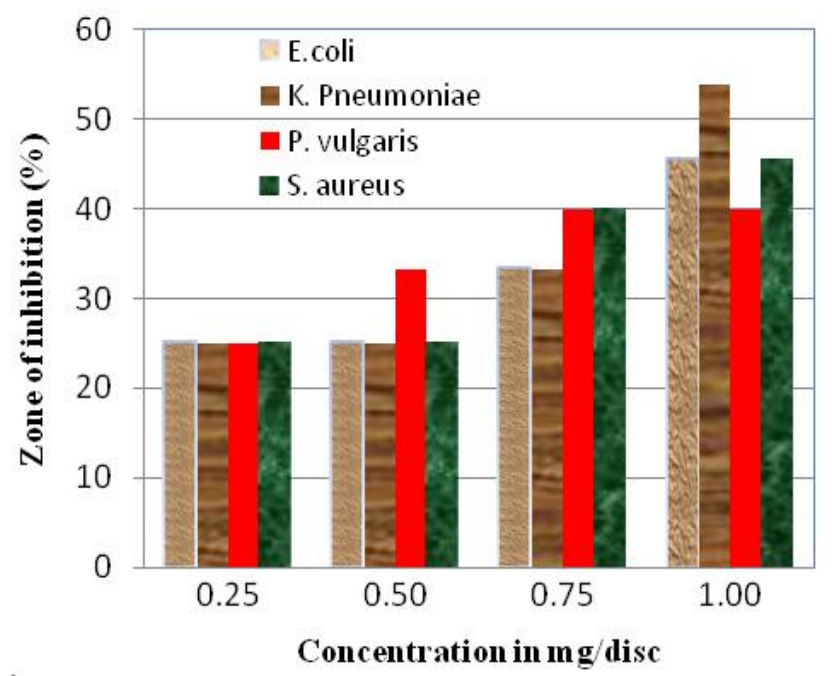

Fig. 2. Antibacterial activities of Acorus calamus $\mathbf{L}$. rhizomes essential oil from Rupandehi district of Nepal

\section{CONCLUSION}

In the present study, we have demonstrated the chemical composition and antibacterial activity of the less studied essential oil of the air dried wild Acorus calamus L. rhizomes from Rupendehi District, Nepal first time. This essential oil exhibited potential antibacterial activity against Gram positive bacteria (Staphylococcus aureus) and Gram negative bacteria (Klebsiella pneumoniae, Escherichia coli and Proteus vulgaris). Because of potential antibacterial activities, pharmacological importance of Acorus calamus L. rhizomes is gradually increasing in the world.

\section{ACKNOWLEDGEMENTS}

Authors are thankful to Central Department of Chemistry, Tribhuvan University, Kirtipur for providing laboratory facilities and Central Department of Microbiology, Tribhuvan University, Kirtipur for antibacterial bioassay.

\section{REFERENCES}

Agarwal, S.L., Dandiya, P.C., Sing, K.P. and Arora, R.B. 1956. A note on the preliminary studies of certain pharmacological actions of Acorus calamus $L$. Journal of the American Pharmaceutical Association 45(9): 655-656.

Balakumbahan, R., Rajamani, K. and Kumanan, K. 2010. Acorus calamus: an overview. Journal of Medicinal Plants Research 4(25): 2740-2745. 
Bauer, A.W., Kirby, W.M.M., Sherris, I.C. and Truck, M. 1960. Antibiotic susceptibility testing by standardized single disk method. American Journal of Clinical Pathology 45(4): 493-496.

Bist, D., Pal, A., Chanitia, C.S., Mishra, D. and Pandey, K.N. 2011.Terpinoid composition and anti fungal activity of three commercial important essential oils against Aspergillus flavus and Aspergillus niger. Natural Product Research 25: 1993-1998.

Gilani, A.U., A. Shah A.J. and Shaheen, F. 2006. Antispasmodic effect of Acorus calamus Linn. Phytother Research 20: 1080-1084.

Gyawali, R. and Kim, K.S. 2009. Volatile organic compound of medicinal values from Nepalese Acorus calamus L. Kathmandu University of Journal of Science and Technology 5: 51-65.

Kim, H., Han, T.H. and Lee, S.G. 2009. Antiinflammatory activity of a water extract of Acorus calamus L. leaves on keratinocyte $\mathrm{HaCaT}$ cells. Journal of Ethnopharmacology 122: 149-156.

Lee, M.H., Chen, Y.Y., Tsai, J.W., Wang, S.C., Watanabe, T. and Tsai, Y.C. 2011. Inhibitory effect of $\beta$-asarone, a component of Acorus calamus essential oil, on inhibition of adipogenesis in 3T3-L1 cells. Food Chemistry 126: 1-7.

Oliver, A.J., Stanton, J. and Taylor, P.J. 1959. A simple filter paper disc method for determining the sensitivity of myco-tuberculosis. Journal of Clinical Pathology 12: 444-447.
Raina, V.K., Srivastab, S. K. and Shyamsunder, K.V. 2003. Essential oils composition of Acorus calamus L. from the lower region of the Himalayas. Flavour Fragrance Journal 18: 18-20.

Rost, L.C.M. and Bos, R. 1979. Biosystematic investigation with Acorus L.-3. Communication constituent of essential oils. Planta Medica 36: 350361.

Satyal, P., Poudel, P., Poudel, A., Dosoky, N.S., Moriarity, D.M., Vogler, B. and Setzer, W.N. 2013. Chemical compositions, phytotoxicity and biological activities of Acorus calamus essential oils from Nepal. Natural Product Communication 8: 1179. 1181.

Si, M.M., Lou, J.S., Zhou, C.X, Hen, J.N. and Wu, H.H. 2010. Insulin releasing and alpha inhibitory activity of ethyl acetate fraction of Acorus calamus in vitro and in vivo. Journal of Ethnopharmacology 28: 154159.

Uprety, R.C., Asselin, H., Boon, E.K., Yadav, S. and Shrestha, K.K. 2011. Indigenoun use and bioefficacy of medicinal plants in the Rasuwa District, central Nepal. Journal of Ethnobiology and Ethnomedical 13: 463-492.

Wu, H.S., Zhu, D.F., Feng, C.R., Lou, Y.J., Yang, B. and He, Q.J. 2009. Insulin sensitizing activity of ethyl acetate fraction of Acorus calamus in vitro and in vivo. Journal Ethnopharmacol 123: 288-292. 